\title{
Multicenter evaluation of the clinical utility of laparoscopy-assisted ERCP in patients with Roux-en-Y gastric bypass
}

Ali M. Abbas MD, MPH ${ }^{1}$, Andrew T. Strong MD², David L. Diehl MD³, Brian C. Brauer MD ${ }^{4}$, Iris H Lee MD ${ }^{5}$, Rebecca Burbridge $\mathrm{MD}^{6}$, Jaroslav Zivny $\mathrm{MD}^{7}$, Jennifer T. Higa MD ${ }^{8}$, Marcelo Falcão MD, $\mathrm{PhD}^{9}$, Ihab I. El Hajj MD, MPH ${ }^{10}$, Paul Tarnasky MD ${ }^{11}$, Brintha K Enestvedt $\mathrm{MD}^{12}$, Alexander R. Ende $\mathrm{MD}^{13}$, Adarsh M Thaker MD ${ }^{14}$, Rishi Pawa MD ${ }^{15}$, Priya Jamidar MD ${ }^{16}$, Kartik Sampath MD ${ }^{17}$, Eduardo Guimarães Hourneaux de Moura $\mathrm{MD}^{18}$, Richard S. Kwon MD ${ }^{19}$, Alejandro L. Suarez MD ${ }^{20}$, Murad Aburajab MD ${ }^{21}$, Andrew Y. Wang MD ${ }^{22}$, Mohammad H. Shakhatreh MD, MPH ${ }^{23}$, Vivek Kaul MD ${ }^{24}$, Lorna Kang BS ${ }^{25}$, Thomas E. Kowalski MD ${ }^{26}$, Rahul Pannala MD ${ }^{27}$, Jeffrey Tokar MD ${ }^{28}$, A. Aziz Aadam $\mathrm{MD}^{29}$, Demetrios Tzimas MD ${ }^{30}$, Mihir S. Wagh MD ${ }^{31}$, Peter V. Draganov MD ${ }^{31}$, and the LA-ERCP research group.

1- University of South Florida Morsani College of Medicine, Tampa, FL USA

2- Cleveland Clinic, Cleveland, OH USA

3- Geisinger Medical Center, Danville, PA USA

4- University of Colorado, Aurora, CO USA

5- University of Maryland School of Medicine, Baltimore, MD USA

6- Duke University, Durham, NC USA

7- University of Massachusetts, Worcester, MA USA

8- Virginia Mason Medical Center, Seattle, WA USA

9- Bahiana School of Medicine and Public Health, Salvador - Bahia, Brazil

10- Indiana University School of Medicine, Indianapolis, IN USA

11- Methodist Dallas Medical Center, Dallas, TX USA

12- Oregon Health \& Science University, Portland, OR USA

13- University of Washington, Seattle, WA USA

14- David Geffen School of Medicine at UCLA, Los Angeles, CA USA

15- Wake Forest Baptist Medical Center, Winston-Salem, NC USA

16- Yale School of Medicine, New Haven, CT USA

17- Dartmouth-Hitchcock Medical Center, Lebanon, NH USA

18- University of São Paulo Medical School, São Paulo Brazil

19- University of Michigan, Ann Arbor, MI USA

20- Medical University of South Carolina, Charleston, SC USA

21- Medical College of Wisconsin, Milwaukee, WI USA

22- University of Virginia, Charlottesville, VA USA

23- Virginia Tech Carilion School of Medicine, Roanoke, VA USA

24- University of Rochester Medical Center, Rochester, NY USA

25- Case Western Reserve University School of Medicine, Cleveland, OH USA

26- Thomas Jefferson University, Philadelphia, PA USA

27- Mayo Clinic Scottsdale, Scottsdale, AZ USA

28- Fox Chase Cancer Center, Philadelphia, PA USA

29- Northwestern University, Chicago, IL USA

30- Stony Brook University School of Medicine, Stony Brook, NY USA

31- University of Florida, Gainesville, FL USA

This is the author's manuscript of the article published in final edited form as:

Abbas, A. M., Strong, A. T., Diehl, D. L., Brauer, B. C., Lee, I. H., Burbridge, R., ... Acker, B. W. (2017). Multicenter evaluation of the clinical utility of laparoscopy-assisted ERCP in patients with Roux-en-Y gastric bypass. 


\section{LA-ERCP research group.}

Jeffrey Ponsky $\mathrm{MD}^{1}$, Bruce D Greenwald $\mathrm{MD}^{2}$, Lance T. Uradomo MD, $\mathrm{MPH}^{2}$, Alyson A. McGhan $\mathrm{MD}^{3}$, Shahrad Hakimian $\mathrm{MD}^{4}$, Andrew Ross MD ${ }^{5}$, Stuart Sherman $\mathrm{MD}^{6}$, Benjamin L. Bick MD ${ }^{6}$, Christopher E. Forsmark $\mathrm{MD}^{7}$, Dennis Yang $\mathrm{MD}^{7}$, Anand Gupte $\mathrm{MD}^{7}$, Shailendra Chauhan $\mathrm{MD}^{7}$, Steven J Hughes $\mathrm{MD}^{7}$, Karen Saks MD ${ }^{8}$, Gennadiy Bakis $\mathrm{MD}^{8}$, Adam W. Templeton MD ${ }^{9}$, Michael Saunders MD ${ }^{9}$, Alireza Sedarat $\mathrm{MD}^{10}$, John A Evans MD ${ }^{11}$, Thiruvengadam Muniraj MD ${ }^{12}$, Timothy B. Gardner $\mathrm{MD}^{13}$, Almino C. Ramos $\mathrm{MD}^{14}$, Marco Aurelio Santo MD ${ }^{15}$, Andrew Nett MD ${ }^{16}$, Gregory A. Coté MD ${ }^{17}$, B. Joseph Elmunzer $\mathrm{MD}^{17}$, Kulwinder S Dua $\mathrm{MD}^{18}$, Michael J Nosler MD ${ }^{19}$, Daniel S. Strand MD ${ }^{20}$, Paul Yeaton $\mathrm{MD}^{21}$, Shivangi Kothari MD ${ }^{22}$, Asad Ullah MD ${ }^{22}$, Pushpak Taunk MD ${ }^{23}$, Patrick Brady MD $^{23}$, Haim Pinkas $\mathrm{MD}^{23}$, Ashley L. Faulx MD ${ }^{24}$, Haroon Shahid MD ${ }^{25}$, Jordan Holmes MD ${ }^{26}$, Davinderbir Pannu $\mathrm{MD}^{27}$, Srinadh Komanduri MD ${ }^{27}$, Juan Carlos Bucobo $\mathrm{MD}^{28}$, Harry Dhaliwal MD ${ }^{29}$, Alaa Rostom $\mathrm{MD}^{29}$, Brent W. Acker MD ${ }^{30}$.

1- Cleveland Clinic, Cleveland, OH USA

2- University of Maryland School of Medicine, Baltimore, MD USA

3- Duke University, Durham, NC USA

4- University of Massachusetts, Worcester, MA USA

5- Virginia Mason Medical Center, Seattle, WA USA

6- Indiana University School of Medicine, Indianapolis, IN USA

7- University of Florida, Gainesville, FL USA

8- Oregon Health \& Science University, Portland, OR USA

9- University of Washington, Seattle, WA USA

10- David Geffen School of Medicine at UCLA, Los Angeles, CA USA

11- Wake Forest Baptist Medical Center, Winston-Salem, NC USA

12- Yale School of Medicine, New Haven, CT USA

13- Dartmouth-Hitchcock Medical Center, Lebanon, NH USA

14- Gastro-Obeso-Center Institute, Sao Paulo, Brazil

15- University of São Paulo Medical School, São Paulo Brazil

16- University of Michigan, Ann Arbor, MI USA

17- Medical University of South Carolina, Charleston, SC USA

18- Medical College of Wisconsin, Milwaukee, WI USA

19- Poudre Valley Hospital, Fort Collins, CO USA

20- University of Virginia, Charlottesville, VA USA

21- Virginia Tech Carilion School of Medicine, Roanoke, VA USA

22- University of Rochester Medical Center, Rochester, NY USA

23- University of South Florida Morsani College of Medicine, Tampa, FL USA

24- University Hospitals Cleveland Medical center, Cleveland, OH USA

25- Thomas Jefferson University, Philadelphia, PA USA

26- Mayo Clinic Scottsdale, Scottsdale, AZ USA

27- Northwestern University, Chicago, IL USA

28- Stony Brook University School of Medicine, Stony Brook, NY USA

29- The University of Ottawa, Ottawa, ON CA

30- University of South Alabama, Mobile, AL USA 
Corresponding Author: to whom requests for reprints should be addressed:

Peter V. Draganov, MD, FACG

Professor of Medicine

Division of Gastroenterology, Hepatology, and Nutrition

University of Florida College of Medicine

1600 SW Archer Rd,

Box 100214

Gainesville, FL 32610

TEL: (352) 273-9400

FAX: (352) 627-9002

Email: Peter.Draganov@medicine.ufl.edu

Acknowledgement of grant support: This is an unfunded work.

Authors contributions: Ali M Abbas, and Peter V. Draganov were involved in study concept and design; acquisition of data; analysis and interpretation of data; drafting of the manuscript; critical revision of the manuscript for important intellectual content; statistical analysis; study supervision. Rest of the authors were involved in concept and design; acquisition of data; and critical revision of the manuscript for important intellectual content.

Disclosure of financial arrangements: Aside from the disclosures listed below, all other authors have no potential conflicts (financial, professional, or personal) that are relevant to this manuscript. The study was conducted and the manuscript was written and reviewed solely by the authors.

Dr. Andrew Y. Wang discloses research support from Cook Medical on the topic of metal biliary stents.

Dr. Mihir S. Wagh is a consultant for Boston Scientific and Medtronic.

Dr. Andrew Ross is a consultant for Boston Scientific.

Dr. A. Aziz Aadam is a consultant for Boston Scientific

Key words: Laparoscopy-Assisted, Endoscopic Retrograde Cholangiopancreatography, Rouxen-Y Gastric Bypass 


\section{Abstract \\ Background and Aims}

The obesity epidemic has led to increased use of Roux-en-Y gastric bypass (RYGB). These patients have an increased incidence of pancreaticobiliary diseases yet standard ERCP is not possible due to surgically altered gastroduodenal anatomy. Laparoscopic-ERCP (LA-ERCP) has been proposed as an option but supporting data are derived from single center small case-series. Therefore, we conducted a large multicenter study to evaluate the feasibility, safety, and outcomes of LA-ERCP.

\section{Methods}

This is retrospective cohort study of adult patients with RYGB who underwent LA-ERCP in 34 centers. Data on demographics, indications, procedure success, and adverse events were collected. Procedure success was defined when all of the following were achieved: reaching the papilla, cannulating the desired duct and providing endoscopic therapy as clinically indicated.

\section{Results}

A total of 579 patients (median age 51, 84\% women) were included. Indication for LA-ERCP was biliary in $89 \%$, pancreatic in $8 \%$, and both in $3 \%$. Procedure success was achieved in $98 \%$. Median total procedure time was 152 minutes (IQR 109-210) with median ERCP time 40 minutes (IQR 28-56). Median hospital stay was 2 days (IQR 1-3). Adverse events were 18\% (laparoscopy-related 10\%, ERCP-related 7\%, both $1 \%$ ) with the clear majority (92\%) classified as mild/moderate whereas $8 \%$ were severe and 1 death occurred.

\section{Conclusion}


Our large multicenter study indicates that LA-ERCP in patients with RYGB is feasible with a high procedure success rate comparable with that of standard ERCP in patients with normal anatomy. ERCP-related adverse events rate is comparable with conventional ERCP, but the overall adverse event rate was higher due to the added laparoscopy-related events.

\section{Background}

The current obesity epidemic has consequently led to an increase in bariatric surgery, with more than 100,000 procedures per year being performed in the United States alone ${ }^{1}$. In recent years, the most common bariatric surgery has been and continues to be Roux-en-Y gastric bypass (RYGB) ${ }^{1,2}$. This operation excludes most of the stomach (ie, remnant stomach) and all of the duodenum making conventional duodenoscopy and per-oral ERCP impossible. Importantly, ERCP is commonly indicated in RYGB patients due to an increased risk of choledocholithiasis and gallstone pancreatitis especially in the setting of rapid weight loss after bariatric surgery ${ }^{3,4}$. Furthermore, several reports have shown increased rate of pancreaticobiliary malignancies in obese patients $^{5,6}$.

Various alternative ERCP approaches for patients with RYGB have been described. Per-oral deep enteroscopy techniques such as single-balloon, double-balloon and spiral enteroscopy are minimally invasive but therapeutic success is far lower compared with standard ERCP. This inferiority is due to the inability to reach the papilla secondary to the surgically altered gastroduodenal anatomy, failure to cannulate the desired duct, or failure to provide therapy due 
to the change of orientation of the papilla, difficult endoscope position, use of forward optics, lack of elevator, small therapeutic channel and/or limited availability of devices ${ }^{7-13}$.

Percutaneous access to the gastric remnant by interventional radiology has been described, but has not gained wide acceptance because it is impractical for urgent cases due to the requirement of serial dilation and track maturation ${ }^{14-16}$. This is further hindered by the inconvenience of needing a gastrostomy tube (G-tube) and the technical difficulties related to the inability to distend the stomach remnant with air ${ }^{6,17}$. EUS-guided transgastric ERCP is another innovative approach ${ }^{18,19}$. However, this methodology has several cited limitations most prominently is the potential for creating a permanent gastro-gastric fistula that compromises the integrity of the

RYGB and the need for 2 stage procedure ${ }^{20-22}$.

Laparoscopy-assisted ERCP (LA-ERCP) is accomplished by placing trocar in the remnant stomach under laparoscopic guidance followed by insertion of the conventional duodenoscope through the trocar to reach the ampulla of Vater. ERCP is then carried out in a standard fashion. The main appeal of LA-ERCP is that it is a single-stage procedure and affords the use of standard ERCP equipment including doudenoscope and accessories. This anticipates a very high procedural success, similar to patients with normal upper GI tract anatomy. LA-ERCP was first described in 2002 and since then, only a few small single-center case series have been published showing high success rates and low adverse events rates ${ }^{6,7,23-25}$. Despite these early encouraging results, the role of LA-ERCP has not been well defined due to a lack of high quality data. Therefore, the aim of this study was to evaluate a large multicenter cohort to assess the feasibility, safety and outcomes of LA-ERCP in patients with RYGB.

\section{Methods}


This is a retrospective multicenter cohort study that included adult patients with RYGB who underwent LA-ERCP between 2005 and 2016. The study was approved by the institutional review board (IRB) of each of the participating centers, with the University of Florida serving as the central coordinating center. All authors had access to the study data and reviewed and approved the final manuscript.

\section{Procedure}

Procedure informed consents for both ERCP and Laparoscopy were obtained from all patients. All procedures were performed in the operating room or designated sterile endoscopy room by both a laparoscopy and endoscopy teams with the patient in supine position under general anesthesia. Percutaneous access with trocar to the remnant stomach was established laparoscopically. Therapeutic duodenoscope was subsequently inserted through the indwelling trocar into the remnant stomach and advanced into the duodenum. ERCP was then carried out in a standard fashion using a conventional duodenoscope and accessories. The gastrostomy and the percutaneous tracts were closed surgically at the end of the procedure or a G-tube is left in place in cases where ERCP might be needed again in the future. All patients were inpatients or were admitted for observation postoperatively.

\section{Data collection}

A standardized data entry form was distributed through secured email across all the centers to collect information on baseline characteristics, intra-procedural and follow-up data. Baseline characteristics included patient demographics, American Society of Anesthesiologists (ASA) class, year and type of RYGB surgery (laparoscopic versus open), cholecystectomy status 
(before LA-ERCP, at the time of LA-ERCP, after the LA-ERCP), prior failed attempts at pancreatico-biliary interventions, indication and type of LA-ERCP (biliary, pancreatic or both).

Procedure-related data included the use of peri-operative antibiotics, total procedure time, ERCP time, the types of ERCP therapeutic interventions (biliary sphincterotomy, dilation of the papilla, dilation of stricture, biliary or pancreatic stent placement or extraction, stone/sludge removal), need for conversion from laparoscopic to open surgery, G-tube placement, and length of hospital stay (LOS).

\section{Definitions}

Procedure success was defined when all of the following were accomplished: reaching the ampulla of Vater, cannulation of the desired duct, and performing the desired therapeutic maneuvers as clinically indicated. Total procedure time was measured from the initial surgical incision to final surgical closure. ERCP time was measured from the scope insertion in the trocar to the scope withdrawal.

Adverse events were classified to either ERCP-related (pancreatitis, cholangitis, sphincterotomyrelated perforation, post-sphincterotomy bleeding, stent migration, or others), or laparoscopyrelated (bleeding, gastric remnant site entry leak, gastric tube site infection, perforation, cardiovascular, other infection, or others). Severity of adverse events was classified using the American Society for Gastrointestinal Endoscopy lexicon as mild, moderate, severe, and death 26.

\section{Statistical analysis}

Data were analyzed using SPSS version 18.0 software (SSPS Inc, Chicago, Ill). Mean, median and interquartile ranges (IQR) were calculated. Categorical data were analyzed using the Fisher 
exact and Chi square testing and continuous data were analyzed using $t$ testing for normally distributed variables and Mann-Whitney U test for non-normally distributed variables.

\section{Results}

Thirty-four centers participated in this study (31 from the United States, 2 from Brazil, and 1 from Canada, Table 1). A total of 579 patients with RYGB (84\% women) with median age of 51 (interquartile range (IQR) 43-61) underwent LA-ERCP during the study period (2005-2016)

(Table 2). The number of procedures performed per year increased noticeably after 2011 reflecting increased adoption of this approach (Figure 1).

Indications for LA-ERCP are outlined in Table 2. Main indications for procedures were: biliary in $89 \%$, pancreatic in $8 \%$ and both biliary and pancreatic in $3 \%$ of the cases. Approximately half (47\%) of all biliary interventions were due to choledocholithiasis whereas acute pancreatitis (93\%) was the most common indication for pancreatic intervention. The most common therapeutic interventions were biliary sphincterotomy (96\%), stone extraction (44\%), and pancreatic stent placement (15\%), (Table 3). Eleven patients (26\%) among those with pancreatic pre-operative indication had stone extraction. Concomitant laparoscopic cholecystectomy was performed in $21 \%$ of the cases and gastric tube was left in place in $17 \%$ of the cases for possible subsequent intervention(s).

Overall procedure success was achieved in $98 \%$. The papilla was successful reached in $99 \%$ and cannulating the desired duct in $98 \%$ of the cases (bile duct cannulation $99 \%$, pancreatic duct cannulation $91 \%$ ). Success rate in performing the desired intervention was $98 \%$ (biliary $99 \%$, pancreatic 89\%). Median total procedure time (laparoscopy + ERCP) was 152 minutes (IQR 109-210 minutes) whereas median ERCP time was 40 minutes (IQR 28-56) minutes. Median 
total procedure time was significantly longer for patient with history of open versus laparoscopic RYGB (181 versus 147 minutes, $\mathrm{p}=0.009)$. Median LOS was 2 (IQR 1-3) days.

Adverse events were reported in 106 out of 579 (18\%) patients. Laparoscopy-related adverse events were reported in 10\% whereas ERCP-related adverse events were reported in $7 \%$ of the patients. One percent of the patients had adverse events related to both laparoscopy and ERCP. The most common laparoscopy associated adverse event was postoperative infections in 24 out of $579(4.1 \%)$, whereas the most common ERCP-related adverse event was acute pancreatitis in 42 out of $579(7.4 \%)$, (Table 4). The rate of pancreatitis varied by the LA-ERCP main indication, among those who had the procedure for biliary indications was $7 \%$. Compared with the rate among those with pancreatic and both (biliary and pancreatic) indications, which was $11 \%$ and $13 \%$, respectively $(\mathrm{p}=0.3$ ). Regarding the severity of these events, $60 \%$ were classified as mild and $31 \%$ as moderate whereas $8 \%$ were classified as severe and one death was reported. In 5\% of the cases ERCP was carried out after conversion to open laparotomy to gain access to the remnant stomach.

We explored the factors associated with laparoscopic versus ERCP-related events by series of univariate analysis as presented in Table 5. Longer duration since RYGB showed a trend towards higher laparoscopy-related events ( $<3$ years had 8\%, 3-6 years had 10\%, 6-9 years had $10 \%$, and those with $>10$ years since RYGB had $16 \%, \mathrm{p}=0.516$ ). Conversion to open laparotomy was associated with significant increase in the risk of laparoscopy-related events ( $24 \%$ versus $10 \%, \mathrm{p}=0.045)$. Leaving a G-tube in place at the end of the procedure was also significantly associate with increased risk of adverse events $(17 \%$ versus $9 \%, \mathrm{p}=0.036)$. These factors (years since RYGB, conversion to open, and leaving G-tube) did not affect the ERCP-related adverse events. 
Most of the patients $(85 \%)$ received peri-operative antibiotics. Antibiotics use was associated with a numerically higher overall adverse events rate $(19 \%$ versus $13 \%, \mathrm{p}=0.198)$, a numerically higher rate of any infectious adverse events $(6.2 \%$ versus $3.4 \%, \mathrm{p}=0.451)$, and a numerically higher rate of $\mathrm{G}$ tube site infection $(1.4 \%$ versus $0 \%, \mathrm{p}=0.603)$.

\section{Discussion}

The feasibility of LA-ERCP has been reported from a few single-center case series, with reported success rate ranging from $80 \%$ to $100 \%$ and adverse events rate ranging from $0 \%$ to $30 \%{ }^{6,7,23-25,27-32}$. These reports are limited by small sample size and heterogeneous definitions of procedure success and adverse events. In our large multicenter study, LA-ERCP in patients with RYGB was highly successful with success rates comparable to standard ERCP in patients with normal upper GI tract anatomy ${ }^{33}$. In our study, the overall success rates in reaching the papilla, cannulating the desired duct and performing the indicated therapeutic intervention was $98 \%$. Furthermore, we also demonstrated that LA-ERCP is feasible and efficient. Our total procedure time (laparoscopy + ERCP) was 152 minutes with median length of hospital stay of 2 days.

In our series, ERCP-related adverse events rate appear comparable with conventional ERCP, although the overall rate of adverse events was higher due to the addition of those attributed to laparoscopy ${ }^{33}$. Importantly, the clear majority (92\%) of the reported adverse events were classified as mild to moderate. Nevertheless, serious adverse events were seen including viscus perforation in 5/579 $(0.8 \%)$ cases. Two patients had sphincterotomy-related duodenal perforations, whereas the rest were laparoscopy-related ( 2 colonic and 1 gastric remnant perforation [trocar perforated the posterior stomach wall]). In one of the perforation cases, multi-organ failure occurred and the patient died after a prolonged hospitalization. 
Placing an indwelling G-tube and conversion to open laparotomy were factors significantly associated with higher laparoscopy-related adverse events. Patients who had G tube left had higher overall laparoscopy associated adverse events $(17 \%$ versus $9 \%, \mathrm{p}=0.03)$. This was attributed to $\mathrm{G}$ tube site infection (6\%), gastric entry-site leak (4\%), and all-causes laparoscopyassociated bleeding (7\%). Of note, all patients who had $\mathrm{G}$ tube site infection did receive perioperative antibiotics as part of their care. Based on these data, it seems reasonable to avoid Gtube insertion unless a repeat procedure is definitely indicated, (Table 5).

Most of the patients included in our series (85\%) received periprocedural antibiotics. There was no statistically significant difference in infection rate between those who received antibiotics versus those who did not. Nevertheless, we cannot exclude any difference based on our findings due to the very low rate of infections and low statistical power to answer this question. Therefore, our data cannot provide definitive guidance for or against the use of perioperative antibiotics.

Our findings are comparable with the recently published systematic review of 26 studies by Banerjee et al that included 509 laparoscopic and open trans-gastric ERCP cases ${ }^{34}$. The success rate in reaching the papilla, cannulation, and performing therapeutic intervention were $98.9 \%$, $98.5 \%$, and $98.5 \%$, respectively. Adverse events were reported in $14 \%$ of cases, with lower G tube site infection (3.7\%) and laparoscopy-associated bleeding (0.9\%), and no reported death compared with our findings ${ }^{34}$.

It is noteworthy that EUS-guided transgastric ERCP is currently an evolving and promising approach that involves deploying lumen-apposing metal stent (LAMS) through the newly formed gastro-gastric fistula ${ }^{18}$. Then the intended ERCP could be performed by passing the endoscope into the remnant stomach through the LAMS ${ }^{18-20}$. This approach can potentially offer great 
advantages including the lack of need for surgical team, minimal invasiveness, and the higher success rate and shorter operative time compared with enteroscopy assisted ERCP. However, this methodology has several cited limitations most prominently the potential for creating a permanent fistula that compromises the integrity of the RYGB ${ }^{20-22}$, high LAMS dislodgement rate $(19 \%)$, and the need for multiple sessions in two-thirds of the patients to allow time for track maturation ${ }^{35}$. Nonetheless, this is a promising approach and direct comparison with LA-ERCP is warranted in future research.

The main strengths of our study include (1) large sample size. (2) Diverse patient population from many centers across the United Sates, Brazil, and Canada. This should improve our findings' external validity by providing more generalizable estimates of success and adverse events rates across many levels of endoscopists' and surgeons' experiences. These estimates can serve as reference to physicians when counseling patients. (3) Standardization of definitions for the outcomes and adverse events. (4) Reporting on all cases done in particular institution thus hopefully decreasing the possibility of selection bias. (5) Our findings are congruent with the findings of earlier smaller studies $6,7,23-25,27-32$.

Laparoscopy-assisted ERCP has the advantage of using standard side-viewing duodenoscope and the standard ERCP accessories, thus increasing the cannulation and therapeutic intervention success rates. Furthermore, because LA-ERCP is done in conjunction with surgeons in the operating room, concomitant cholecystectomy can be performed if clinically indicated. In our population, concomitant cholecystectomy was performed in $20 \%$. Saleem et $\mathrm{al}^{25}$ reported performing concomitant cholecystectomy in $20 \%$ of the patients. Additionally, laparoscopic approach allows the diagnosis and treatment of internal hernias (reported in 20\%-40\%) and adhesions (in $20 \%$ ) of the LA-ERCP procedures ${ }^{23,25}$. 
Nonetheless, there are several challenging aspects of LA-ERCP that must be addressed before adoption of this procedure by a medical center. The center must have expertise in bariatric surgery as well as advanced endoscopy. Secondly, maintaining sterility, the lay out of the OR, and its equipment are different from what the endoscopy team is accustomed to in the usual endoscopy suites ${ }^{25}$. Thus, a special protocol has to be devised and taught to the endoscopy team 25. In addition, a great deal of schedule coordination is required to ensure that the endoscopist and the surgeon along with their teams are present in the OR at the same time to avoid delays ${ }^{25}$. At the University of Florida and The Cleveland Clinic, the LA-ERCPs are typically scheduled as the first cases of the day to ensure that the 2 teams are available and there would be no interference with the rest of the OR and endoscopy schedules.

Our study has the typical limitations inherent to retrospective design related to potential for patient selection bias, and measurement bias particularly the under-reporting of adverse events. We anticipate that underreporting was minimized in our cohort because all of our patients were inpatients or were admitted to the hospital after surgery, making detection and reporting of adverse events more likely. In addition, for clarity of reporting we divided adverse events into ERCP or laparoscopy-related categories. Such a distinction may be straightforward for most adverse events such as post-ERCP pancreatitis but could be arbitrary for others such as cardiovascular compromise. Nevertheless, the reported overall adverse event rate should provide an accurate estimate to use as a guide for physicians and patients.

Our large multicenter study indicates that LA-ERCP in patients with RYGB is highly successful, with success rates comparable to standard ERCP in patients with normal upper GI tract anatomy. ERCP-related adverse event rates also appear comparable with those expected of conventional ERCP, but the overall adverse events rate was higher due to the addition of laparoscopy- related 
events. Although the majority of such events were mild to moderate, rare severe adverse events are possible. Given the exceptionally high technical success rate and acceptable safety profile, LA-ERCP can be considered as one of the first-line approaches in patients with RYGB who require ERCP. Comparative studies with alternative procedures such as EUS-guided gastrogastrostomy may further refine our approach in this very challenging patient population.

\section{References}

1. Livingston EH. The incidence of bariatric surgery has plateaued in the U.S. Am J Surg. 2010;200:378-385.

2. Livingston EH. Procedure incidence and in-hospital complication rates of bariatric surgery in the United States. Am J Surg. 2004;188:105-110.

3. Hamdan K, Somers S, Chand M. Management of late postoperative complications of bariatric surgery. Br J Surg. 2011;98:1345-1355.

4. Miller K, Hell E, Lang B, Lengauer E. Gallstone formation prophylaxis after gastric restrictive procedures for weight loss: a randomized double-blind placebo-controlled trial. Ann Surg. 2003;238:697-702.

5. Calle EE, Rodriguez C, Walker-Thurmond K, Thun MJ. Overweight, obesity, and mortality from cancer in a prospectively studied cohort of U.S. adults. N Eng/ J Med. 2003;348:1625-1638.

6. Ceppa FA, Gagné DJ, Papasavas PK, Caushaj PF. Laparoscopic transgastric endoscopy after Rouxen-Y gastric bypass. Surg Obes Relat Dis. 2007;3:21-24.

7. Schreiner MA, Chang L, Gluck M, et al. Laparoscopy-assisted versus balloon enteroscopyassisted ERCP in bariatric post-Roux-en-Y gastric bypass patients. Gastrointest Endosc. 2012;75:748-756.

8. Shah RJ, Smolkin M, Yen R, et al. A multicenter, U.S. experience of single-balloon, doubleballoon, and rotational overtube-assisted enteroscopy ERCP in patients with surgically altered pancreaticobiliary anatomy (with video). Gastrointest Endosc. 2013;77:593-600.

9. Skinner M, Popa D, Neumann H, Wilcox CM, Mönkemüller K. ERCP with the overtube-assisted enteroscopy technique: a systematic review. Endoscopy. 2014;46:560-572.

10. Saleem A, Baron TH, Gostout CJ, et al. Endoscopic retrograde cholangiopancreatography using a single-balloon enteroscope in patients with altered Roux-en-Y anatomy. Endoscopy. 2010;42:656-660.

11. Freeman ML, Guda NM. ERCP cannulation: a review of reported techniques. Gastrointest Endosc. 2005;61:112-125.

12. Amer S, Horsley-Silva JL, Menias CO, Pannala R. Endoscopic retrograde cholangiopancreatography in patients with surgically altered gastrointestinal anatomy. Abdom Imaging. 2015;40:2921-2931.

13. Wright BE, Cass OW, Freeman ML. ERCP in patients with long-limb Roux-en-Y gastrojejunostomy and intact papilla. Gastrointest Endosc. 2002;56:225-232.

14. Fobi MA, Chicola K, Lee H. Access to the bypassed stomach after gastric bypass. Obes Surg. 1998;8:289-295.

15. Martinez J, Guerrero L, Byers $P$, et al. Endoscopic retrograde cholangiopancreatography and gastroduodenoscopy after Roux-en-Y gastric bypass. Surg Endosc. 2006;20:1548-1550. 
16. Choi EK, Chiorean MV, Coté GA, et al. ERCP via gastrostomy vs. double balloon enteroscopy in patients with prior bariatric Roux-en-Y gastric bypass surgery. Surg Endosc. 2013;27:2894-2899.

17. Sundbom M, Nyman R, Hedenström $H$, Gustavsson $S$. Investigation of the excluded stomach after Roux-en-Y gastric bypass. Obes Surg. 2001;11:25-27.

18. Kedia P, Sharaiha RZ, Kumta NA, Kahaleh M. Internal EUS-directed transgastric ERCP (EDGE): game over. Gastroenterology. 2014;147:566-568.

19. Kedia P, Kumta NA, Sharaiha R, Kahaleh M. Bypassing the bypass: EUS-directed transgastric ERCP for Roux-en-Y anatomy. Gastrointest Endosc. 2015;81:223-224.

20. Tyberg A, Nieto J, Salgado S, et al. Endoscopic Ultrasound (EUS)-Directed Transgastric Endoscopic Retrograde Cholangiopancreatography or EUS: Mid-Term Analysis of an Emerging Procedure. Clin Endosc. 2016.

21. Diehl DL, Gabrielsen JD, Strodel WE. The challenges of endoscopic retrograde cholangiopancreatography in gastric bypass patients: the game is not yet over. Gastroenterology. 2015;148:857-858.

22. Abu Dayyeh BK, Thompson CC, Gostout C. Endoscopic Retrograde Cholangiopancreatography After Roux-en-Y Gastric Bypass: Challenges and Cautions. Gastroenterology. 2015;148:858-859.

23. Lopes TL, Clements RH, Wilcox CM. Laparoscopy-assisted ERCP: experience of a high-volume bariatric surgery center (with video). Gastrointest Endosc. 2009;70:1254-1259.

24. Roberts KE, Panait L, Duffy AJ, Jamidar PA, Bell RL. Laparoscopic-assisted transgastric endoscopy: current indications and future implications. JSLS. 2008;12:30-36.

25. Saleem A, Levy MJ, Petersen BT, Que FG, Baron TH. Laparoscopic assisted ERCP in Roux-en-Y gastric bypass (RYGB) surgery patients. J Gastrointest Surg. 2012;16:203-208.

26. Cotton PB, Eisen GM, Aabakken L, et al. A lexicon for endoscopic adverse events: report of an ASGE workshop. Gastrointest Endosc. 2010;71:446-454.

27. Bowman E, Greenberg J, Garren M, et al. Laparoscopic-assisted ERCP and EUS in patients with prior Roux-en-Y gastric bypass surgery: a dual-center case series experience. Surg Endosc. 2016;30:4647-4652.

28. Falcão M, Campos JM, Galvão Neto $M$, et al. Transgastric endoscopic retrograde cholangiopancreatography for the management of biliary tract disease after Roux-en-Y gastric bypass treatment for obesity. Obes Surg. 2012;22:872-876.

29. Snauwaert C, Laukens P, Dillemans B, et al. Laparoscopy-assisted transgastric endoscopic retrograde cholangiopancreatography in bariatric Roux-en-Y gastric bypass patients. Endosc Int Open. 2015;3:E458-463.

30. Grimes KL, Maciel VH, Mata W, Arevalo G, Singh K, Arregui ME. Complications of laparoscopic transgastric ERCP in patients with Roux-en-Y gastric bypass. Surg Endosc. 2015;29:1753-1759.

31. Richardson JF, Lee JG, Smith BR, Nguyen B, Pham KP, Nguyen NT. Laparoscopic transgastric endoscopy after Roux-en-Y gastric bypass: case series and review of the literature. Am Surg. 2012;78:1182-1186.

32. Bertin PM, Singh K, Arregui ME. Laparoscopic transgastric endoscopic retrograde cholangiopancreatography (ERCP) after gastric bypass: case series and a description of technique. Surg Endosc. 2011;25:2592-2596.

33. Szary NM, Al-Kawas FH. Complications of endoscopic retrograde cholangiopancreatography: how to avoid and manage them. Gastroenterol Hepatol (N Y). 2013;9:496-504.

34. Banerjee N, Parepally M, Byrne TK, Pullatt RC, Coté GA, Elmunzer BJ. Systematic review of transgastric ERCP in Roux-en-Y gastric bypass patients. Surg Obes Relat Dis. 2017;13:1236-1242.

35. Park SW. Commentary on "Endoscopic Ultrasound (EUS)-Directed Transgastric Endoscopic Retrograde Cholangiopancreatography or EUS". Clin Endosc. 2017;50:102-103. 
Table 1: Participating Centers

\begin{tabular}{|c|c|c|c|c|}
\hline Center name & City & State & Country & Patients \\
\hline Cirurgia Digestiva e Obesidade & Salvador & Bahia & Brazil & 26 \\
\hline Cleveland Clinic & Cleveland & $\mathrm{OH}$ & USA & 52 \\
\hline Dartmouth-Hitchcock Medical Center & Lebanon & $\mathrm{NH}$ & USA & 14 \\
\hline Duke University & Durham & $\mathrm{NC}$ & USA & 28 \\
\hline Fox Chase Cancer Center & Philadelphia & PA & USA & 6 \\
\hline Geisinger Medical Center & Danville & PA & USA & 49 \\
\hline Indiana University & Indianapolis & IN & USA & 24 \\
\hline Mayo Clinic Scottsdale & Scottsdale & $\mathrm{AZ}$ & USA & 7 \\
\hline Medical College of Wisconsin & Milwaukee & WI & USA & 11 \\
\hline Medical University of South Carolina & Charleston & $\mathrm{SC}$ & USA & 12 \\
\hline Methodist Dallas Medical Center & Dallas & $\mathrm{TX}$ & USA & 23 \\
\hline Northwestern University & Chicago & $\mathrm{IL}$ & USA & 6 \\
\hline Oregon Health \& Science University & Portland & OR & USA & 17 \\
\hline Poudre Valley Hospital & Fort Collins & $\mathrm{CO}$ & USA & 10 \\
\hline Stony Brook University School of Medicine & Stony Brook & NY & USA & 5 \\
\hline The University of Ottawa & Ottawa & $\mathrm{ON}$ & CA & 3 \\
\hline Thomas Jefferson University & Philadelphia & $\mathrm{PA}$ & USA & 8 \\
\hline University Hospitals Case Medical Center & Cleveland & $\mathrm{OH}$ & USA & 8 \\
\hline University of California Los Angeles (UCLA) & Santa Monica & $\mathrm{CA}$ & USA & 16 \\
\hline University of Colorado, Denver & Denver & $\mathrm{CO}$ & USA & 36 \\
\hline University of Florida & Gainesville & $\mathrm{FL}$ & USA & 20 \\
\hline University of Maryland School of Medicine & Baltimore & MD & USA & 30 \\
\hline University of Massachusetts & Worcester & MA & USA & 28 \\
\hline University of Michigan & Ann Arbor & MI & USA & 14 \\
\hline University of Rochester Medical Center & Rochester & NY & USA & 8 \\
\hline University of São Paulo Medical School & São Paulo & São & Brazil & 14 \\
\hline Gastro-Obeso-Center Institute & & Paulo & & \\
\hline University of South Alabama & Mobile & AL & USA & 2 \\
\hline University of South Florida & Tampa & FL & USA & 8 \\
\hline University of Virginia & Charlottesville & VA & USA & 10 \\
\hline University of Washington & Seattle & WA & USA & 17 \\
\hline Virginia Mason Medical Center & Seattle & WA & USA & 28 \\
\hline Virginia Tech Carilion School of Medicine & Roanoke & VA & USA & 9 \\
\hline Wake Forest Baptist Medical Center & Winston Salem & $\mathrm{NC}$ & USA & 16 \\
\hline Yale School of Medicine & New Haven & $\mathrm{CT}$ & USA & 14 \\
\hline
\end{tabular}


Table 2: Demographics and other clinical factors of the included population

\begin{tabular}{|c|c|c|c|}
\hline & & No. & $\%$ \\
\hline \multirow[t]{4}{*}{ Age quartile } & $<42$ & 144 & $25 \%$ \\
\hline & $42-51$ & 148 & $26 \%$ \\
\hline & $52-61$ & 157 & $27 \%$ \\
\hline & $>61$ & 130 & $22 \%$ \\
\hline \multirow[t]{2}{*}{ Gender } & Female & 488 & $84 \%$ \\
\hline & Male & 91 & $16 \%$ \\
\hline \multirow[t]{4}{*}{ ASA class } & 1 & 4 & $1 \%$ \\
\hline & 2 & 242 & $44 \%$ \\
\hline & 3 & 291 & $53 \%$ \\
\hline & 4 & 14 & $3 \%$ \\
\hline \multirow[t]{2}{*}{ Type bariatric surgery } & Laparoscopic Roux-en-Y gastric bypass & 340 & $68 \%$ \\
\hline & Open Roux-en-Y gastric bypass & 160 & $32 \%$ \\
\hline \multirow[t]{4}{*}{ Years since RYGB, quartiles } & $<3$ & 146 & $30 \%$ \\
\hline & 3-6 & 106 & $22 \%$ \\
\hline & 7-10 & 125 & $25 \%$ \\
\hline & $>10$ & 116 & $24 \%$ \\
\hline \multirow[t]{3}{*}{ Cholecystectomy } & Before ERCP & 423 & $78 \%$ \\
\hline & At the time of ERCP & 114 & $21 \%$ \\
\hline & After ERCP & 6 & $1 \%$ \\
\hline \multirow{5}{*}{$\begin{array}{l}\text { Prior failed attempts of } \\
\text { pancreaticobiliary interventions }\end{array}$} & No prior attempt reported & 438 & $76 \%$ \\
\hline & Enteroscopy ERCP & 109 & $19 \%$ \\
\hline & PTC & 26 & $4 \%$ \\
\hline & Laparoscopic bile duct exploration & 5 & $1 \%$ \\
\hline & Open bile duct exploration & 1 & $0 \%$ \\
\hline \multirow[t]{3}{*}{ Main Indication } & Biliary & 518 & $89 \%$ \\
\hline & Pancreatic & 45 & $8 \%$ \\
\hline & Both & 16 & $3 \%$ \\
\hline \multirow[t]{11}{*}{ Biliary indication } & Biliary stone & 254 & $47 \%$ \\
\hline & Suspected papillary stenosis & 102 & $19 \%$ \\
\hline & Dilated duct & 75 & $14 \%$ \\
\hline & Abnormal LFTs & 46 & $9 \%$ \\
\hline & Bile duct stricture & 20 & $4 \%$ \\
\hline & Post cholecystectomy pain & 10 & $2 \%$ \\
\hline & Others/abdominal pain & 9 & $2 \%$ \\
\hline & Bile leak & 7 & $1 \%$ \\
\hline & Ampullary lesion & 7 & $1 \%$ \\
\hline & Biliary stent removal & 3 & $1 \%$ \\
\hline & Abnormal intraoperative cholangiogram & 2 & $0 \%$ \\
\hline \multirow[t]{3}{*}{ Pancreatic Indications } & Pancreatitis & 56 & $93 \%$ \\
\hline & Dilated pancreatic duct & 3 & $5 \%$ \\
\hline & Pancreatic duct stone & 1 & $2 \%$ \\
\hline \multirow[t]{2}{*}{ Peri-operative antibiotics } & No & 89 & $15 \%$ \\
\hline & Yes & 489 & $85 \%$ \\
\hline \multirow[t]{2}{*}{ LA-ERCP goal } & Therapeutic & 574 & $99 \%$ \\
\hline & Diagnostic & 5 & $1 \%$ \\
\hline
\end{tabular}

Notes, LA-ERCP: Laparoscopy assisted ERCP. 
Table 3: Interventions performed during LA-ERCP.

\begin{tabular}{lrr}
\hline & No. & $\%$ \\
\hline Biliary sphincterotomy & 550 & $96 \%$ \\
Stone/sludge/cast extraction & 253 & $44 \%$ \\
Pancreatic duct stent placement & 88 & $15 \%$ \\
Dilation of the papilla & 82 & $14 \%$ \\
Dilation of the ampullary orifice with large balloon $(\mathbf{1 2} \mathbf{~ m m})$ & 48 & $8 \%$ \\
Plastic biliary stent placement & 32 & $6 \%$ \\
Pancreatic stent extraction & 10 & $2 \%$ \\
Biliary stent extraction & 20 & $3 \%$ \\
Dilation of a stricture & 17 & $3 \%$ \\
Metal biliary stent placement & 6 & $1 \%$ \\
\hline
\end{tabular}


Table 4: Adverse events

\begin{tabular}{lrr}
\hline Laparoscopy related & & \\
\hline Other postoperative infections & $24 / 579$ & $4.1 \%$ \\
Laparoscopy-related bleeding & $10 / 579$ & $1.7 \%$ \\
Gastric site leak & $7 / 579$ & $1.2 \%$ \\
Gastric tube site infection & $7 / 579$ & $1.2 \%$ \\
Postoperative respiratory adverse events & $6 / 579$ & $1.0 \%$ \\
Postoperative cardiovascular adverse events & $4 / 579$ & $0.7 \%$ \\
Laparoscopy related perforation & $3 / 579$ & $0.5 \%$ \\
Other laparoscopic related adverse event & $11 / 579$ & $1.9 \%$ \\
\hline ERCP-related & & \\
\hline Pancreatitis & $43 / 579$ & $7.4 \%$ \\
Cholangitis & $6 / 579$ & $1.0 \%$ \\
ERCP-related bleeding & $3 / 579$ & $0.5 \%$ \\
ERCP-related perforation & $2 / 579$ & $0.3 \%$ \\
Stent migration & $1 / 579$ & $0.2 \%$ \\
\hline
\end{tabular}


Table 5: Subgroup analyses of adverse events

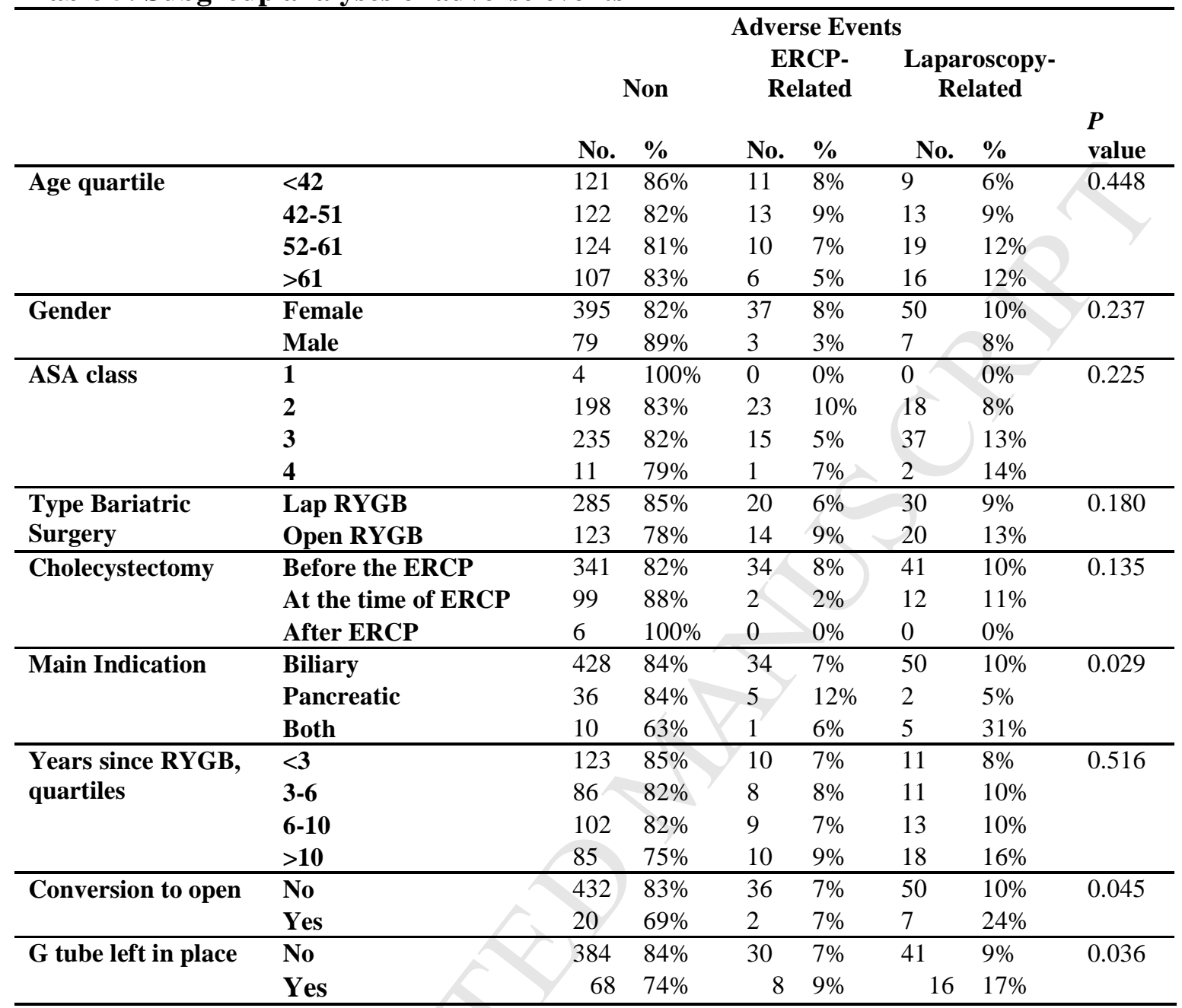

Note: patients who had both ERCP and laparoscopy related adverse events were excluded from this analysis (8 patients). $P$ values are derived from comparing the distribution of adverse event across all the groups within the same variable. 


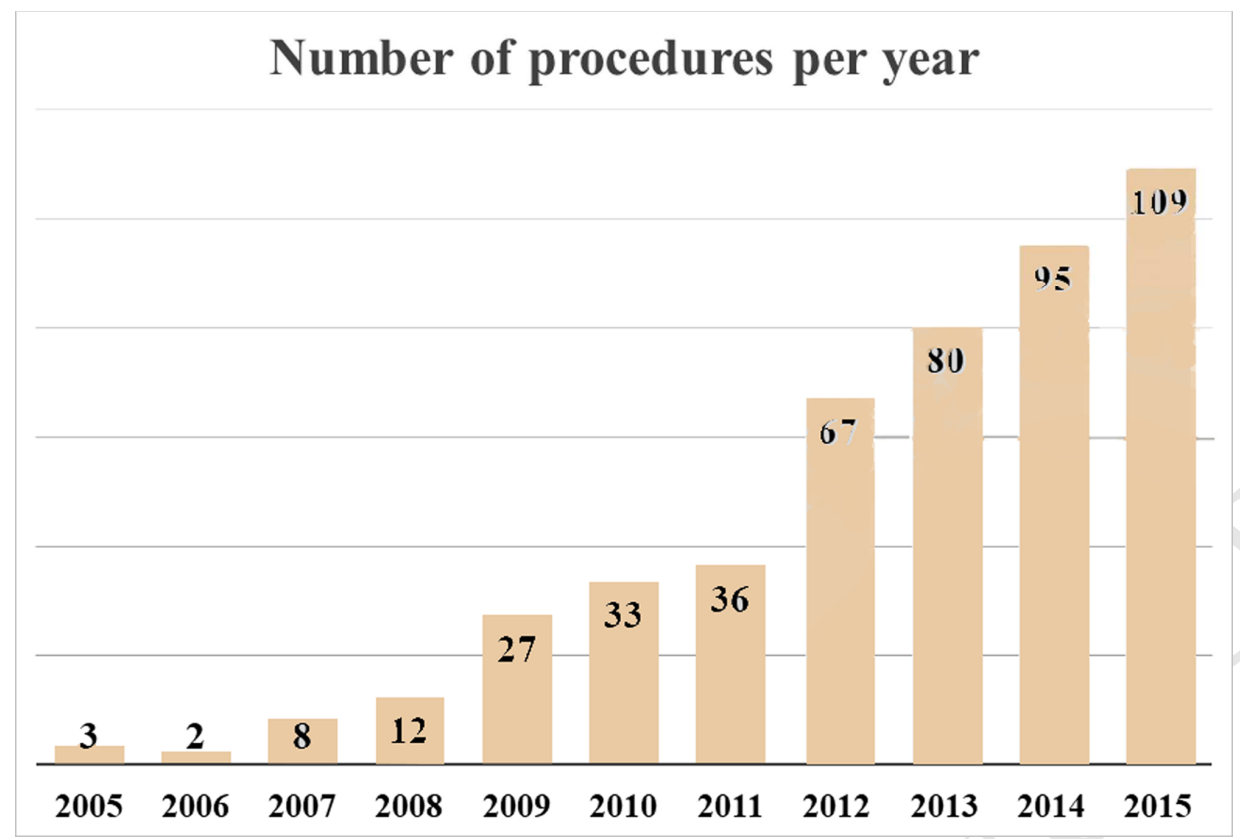


LA-ERCP = Laparoscopy-Assisted Endoscopic Retrograde Cholangiopancreatography RYGB = Patients with Roux-en-Y Gastric Bypass

G-tube $=$ gastrostomy tube

IRB = institutional review board

LOS $=$ length of hospital stay

$\mathrm{IQR}=$ interquartile ranges 